\title{
PATTERN OF SUBSTANCE USE IN A DRUG DEADDICTION CENTRE IN DIPHU- NORTHEAST INDIA- BASED STUDY
}

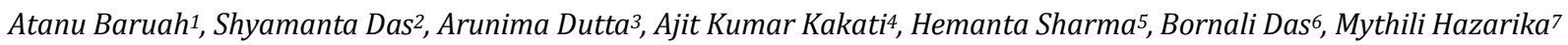 \\ ${ }_{1}^{1}$ Assistant Professor of Surgery, Department of Emergency Medicine, Gauhati Medical College Hospital, Guwahati, Assam, India. \\ ${ }^{2}$ Assistant Professor, Department of Psychiatry, Gauhati Medical College Hospital, Guwahati, Assam, India. \\ ${ }^{3}$ Resident, McLaren Flint, Michigan, USA. \\ ${ }^{4}$ Sub-divisional Medical and Health Officer, Haflong Civil Hospital, Haflong, Dima Hasao, Assam, India. \\ ${ }^{5}$ Lecturer of Psychiatric Social Work, Department of Psychiatry, Gauhati Medical College Hospital, Guwahati, Assam, India. \\ ${ }^{6}$ Senior Lecturer of Psychiatric Social Work, Department of Psychiatry, Gauhati Medical College Hospital, Guwahati, Assam, India. \\ ${ }^{7}$ Associate Professor of Clinical Psychology, Department of Psychiatry, Gauhati Medical College Hospital, Guwahati, Assam, India.
}

\section{BACKGROUND}

ABSTRACT

India is a multicultural and multilingual democracy; the use of different substances is found to be regionally diversified. Ethnic variations have contributed to this diversification and so a single study on a particular region cannot be generalised to the whole Indian population. Alcohol is one of the most popular substances used in India which can be traced backed to the scriptures. The local homemade liquor is the most common form of liquor used by the Indian population. The traditional winemaking process is common among the different ethnic tribes of Northeast India and thus most of the alcohol use is unrecorded in this part of the country.

\section{MATERIALS AND METHODS}

An observational study was conducted in the Drug Deaddiction Centre of Diphu Civil Hospital, Assam where patients' recorded data over a four-year period was used. The data was reviewed retrospectively to understand the pattern of substance use in this region and the results were described using descriptive statistics.

\section{RESULTS}

Alcohol was found to be the most used substance and significant gender difference was noted among the users. Both tribal and nontribal groups were almost equally seen to use alcohol while around one-fifth of the population belonged to the age group of less than 30 years. Early initiation of alcohol use due to cultural reasons was suspected. Various health issues ranging from gastrointestinal (GI) symptoms to death due to alcohol misuse were reported. Due to the retrospective review process, missing data was found to be a significant limitation to this study.

\section{CONCLUSION}

Adequate health promotion focusing on effects of alcohol on health should be undertaken in this region and proper follow-up of the treated patients should be done to prevent relapse.

\section{KEY WORDS}

Substance Abuse, Tribes, Alcohol

HOW TO CITE THIS ARTICLE: Baruah A, Das S, Dutta A, et al. Pattern of substance use in a drug deaddiction centre in DiphuNortheast India-based study. J. Evolution Med. Dent. Sci. 2019;8(12):855-858, DOI: 10.14260/jemds/2019/190

\section{BACKGROUND}

Northeast India is a hub of 130 major tribal communities of India. Diphu, a district headquarter of Karbi Anglong District of Assam, hosts different tribes like Karbi, Kachari, Adivasi, Bodo along with non-tribal groups like Assamese, Bengali, Bihari. As per a Northeast-based study by Medhi et al.,[1] alcohol is usually initiated by 25 years of age among the ethnic groups of India. Unrecorded alcohol (homemade or informally produced alcohol) constitutes around more than $50 \%$ of alcohol used in the South East Asian Region (SEAR),

'Financial or Other Competing Interest': None.

Submission 05-01-2019, Peer Review 04-03-2019,

Acceptance 12-03-2019, Published 25-03-2019.

Corresponding Author:

Shyamanta Das,

\#10, C. K. Agarwalla Road,

Ambari, Uzan Bazar,

Guwahati-781001,

Assam, India.

E-mail:dr.shyamantadas@gmail.com

DOI: $10.14260 /$ jemds $/ 2019 / 190$
Eastern Mediterranean region, and the low-income countries like India.[2] With the rise in the economy of a country, alcohol use increases but the proportion of unrecorded alcohol consumption decreases.[2] Currently, the total adult per capita use of alcohol is 3.4 in SEAR countries compared to 6.2 globally.[2] Alcohol has been proved to have a strong impact on physical and mental health as well social interaction of an individual. As substance use is initially started at a young age out of curiosity, frequent use inculcates into a habit which later on may pose a threat to the global wellbeing of the individual. Alcohol is attributable to around $4.5 \%$ of global burden of disease and injury and is the third highest risk of disease and disability.[2] It is also associated with domestic violence, child neglect, and other social issues.[2]

\footnotetext{
Aim of The Study

The study was conducted in order to assess the pattern of substance use in the area covered by the Drug Deaddiction Centre (DDC) of Diphu Civil Hospital in order to streamline programmes in the same pattern.
} 


\section{Statement}

The pattern of substance use among the population covered by the DDC of Diphu Civil Hospital.

\section{Objectives}

1. To assess substance use pattern in relation to age and sex.

2. Substance use pattern among tribes.

3. Effect of substance use on health.

4. Duration of stay in hospital.

\section{MATERIALS AND METHODS}

\section{Type of Study}

Observational study.

\section{Tools Used}

Socio-demographic data, the tenth revision of International Statistical Classification of Diseases and Related Health Problems (ICD 10).[3]

\section{Procedure}

Charts of patients attending DDC of Diphu Civil Hospital during the period of 1 January 2011 to 10 September 2014 were reviewed. Being a retrospective chart review study, informed consent did not apply. Ethical clearance was exempt as this was an observational study.

\section{Statistical Analysis}

Descriptive statistics were used to interpret the results.

\section{RESULTS}

Out of the 307 samples taken, $54.86 \%$ were from the age range of $31-45$ years, $22.97 \%$ from $46-60$ years, and $16.49 \%$ among $16-30$ years of age; only $5.95 \%$ patients were females (Table 1).

\begin{tabular}{|c|c|c|}
\hline & Total & Percentage \\
\hline \multicolumn{3}{|c|}{ Age (Years) } \\
\hline $16-30$ & 61 & 16.49 \\
\hline $31-45$ & 203 & 54.86 \\
\hline $46-60$ & 85 & 22.97 \\
\hline $61-75$ & 21 & 5.68 \\
\hline \multicolumn{3}{|c|}{ Sex } \\
\hline Females & 22 & 5.95 \\
\hline Males & 348 & 94.05 \\
\hline \multicolumn{2}{|c|}{ Table 1. Age and Sex Distribution (n=370) } \\
\hline
\end{tabular}

Among the people of the lowest age group, two presented with acute alcohol intoxication, three with opioid use, and one with multiple psychoactive substance use. Majority of patients among all age groups presented with alcohol dependence and withdrawal. Compared to males, females abusing substance were less in number in this study (Table 2).

\begin{tabular}{|c|c|c|c|c|c|c|c|c|c|c|}
\hline & $\stackrel{\pi}{0}$ & $\underset{\Gamma}{\stackrel{0}{r}}$ & $\stackrel{0}{\stackrel{0}{0}}$ & Nָ & 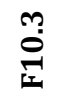 & 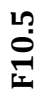 & 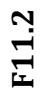 & $\stackrel{n}{\stackrel{n}{I}}$ & $\frac{a}{I}$ & $\frac{\sim}{a}$ \\
\hline \multicolumn{11}{|c|}{ Age (years) } \\
\hline $16-30$ & 61 & 14 & 2 & 17 & 20 & 3 & 1 & 2 & 0 & 1 \\
\hline $31-45$ & 201 & 37 & 2 & 75 & 76 & 8 & 0 & 1 & 1 & 1 \\
\hline \begin{tabular}{|l|}
$46-60$ \\
\end{tabular} & 83 & 11 & 1 & 33 & 33 & 4 & 0 & 0 & 1 & 0 \\
\hline $61-75$ & 20 & 7 & 0 & 6 & 6 & 1 & 0 & 0 & 0 & 0 \\
\hline \multicolumn{11}{|c|}{ Sex } \\
\hline Female & 22 & 3 & 8 & 8 & 1 & 0 & 0 & 1 & 0 & 1 \\
\hline Male & 342 & 66 & 123 & 127 & 15 & 1 & 3 & 1 & 2 & 4 \\
\hline \multicolumn{11}{|c|}{${ }^{*}$ There is missing data } \\
\hline & & & Ige & ad & 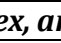 & & & & & \\
\hline
\end{tabular}

Ascites was found to be the most commonly associated clinical finding with alcohol-related disorders while gastrointestinal (GI) symptoms like melaena, hematemesis, gastritis was also found in most patients. Neuropathy was also noted in a few patients while two presented with hypoglycaemia. Five patients presented with fever and one with respiratory disease. One patient with alcohol withdrawal was reported dead. Two patients with schizophrenia presented with alcohol dependence (Table 3).

\begin{tabular}{|c|c|c|c|}
\hline $\begin{array}{l}\text { Substance } \\
\text { Abuse }\end{array}$ & Total & Comorbidity & Total \\
\hline \multirow{3}{*}{ F10 } & \multirow{3}{*}{69} & Semi-Consciousness & 2 \\
\hline & & Ascites & 20 \\
\hline & & Fever & 4 \\
\hline F10.0 & 5 & & \\
\hline \multirow{6}{*}{ F10.2 } & \multirow{6}{*}{131} & Ascites & 4 \\
\hline & & Hypertension & 3 \\
\hline & & Hypoglycaemia & 1 \\
\hline & & Melena & 2 \\
\hline & & Neuropathy & 1 \\
\hline & & $\begin{array}{l}\text { Respiratory Tract } \\
\text { Infection }\end{array}$ & 1 \\
\hline & & Schizophrenia & 2 \\
\hline \multirow{11}{*}{ F10.3 } & \multirow{11}{*}{135} & Acute gastritis & 1 \\
\hline & & Ascites & 2 \\
\hline & & Haematemesis & 1 \\
\hline & & Hypertension & 1 \\
\hline & & Melena & 1 \\
\hline & & Death & 1 \\
\hline & & \begin{tabular}{|l} 
Chronic Obstructive \\
Pulmonary Disease \\
\end{tabular} & 1 \\
\hline & & Fever & 1 \\
\hline & & Hyperbilirubinaemia & 1 \\
\hline & & \begin{tabular}{|l|} 
Hypoglycaemia \\
\end{tabular} & 1 \\
\hline & & Neuropathy & 1 \\
\hline F10.5 & 16 & Hypertension & 2 \\
\hline
\end{tabular}

The maximum duration of stay was noted to be 33 days and one day was the minimum while the mode was three days. Hindus were majority in this sample. Sample was almost equally distributed between the tribal and non-tribal groups (Table 4). 


\begin{tabular}{|c|c|}
\hline & Number \\
\hline Duration of Stay (Days) \\
\hline Maximum & 33 \\
\hline Minimum & 1 \\
\hline Mode & 3 \\
\hline Hindu & 335 \\
\hline Muslim & 16 \\
\hline Christian & 9 \\
\hline \multicolumn{2}{|c|}{ Caste* } \\
\hline Tribal & 151 \\
\hline Nontribal & 146 \\
\hline \multicolumn{2}{|c|}{$*$ There is missing data } \\
\hline Table 4. Duration of Stay, Religion, and Caste \\
\hline
\end{tabular}

Eight tribal people showed mental changes associated with alcohol use while only three nontribal showed similar finding (Table 5).

\begin{tabular}{|c|c|c|c|c|c|}
\hline Caste & F10 & F10.0 & F10.2 & F10.3 & F10.5 \\
\hline Non-Tribal & 35 & 2 & 44 & 58 & 3 \\
\hline Tribal & 29 & 1 & 54 & 53 & 8 \\
\hline \multicolumn{6}{|c|}{ *There is missing data } \\
\hline \multicolumn{3}{|c|}{ Table 5aste and Type of Substance Use ${ }^{*}$} \\
\hline
\end{tabular}

\section{DISCUSSION}

The study showed a high percentage of alcohol use compared to other psychoactive substances and opioids. The highest amount of substance use was noted among the middle-aged population. Male to female ratio was $18.8 \%$. This huge difference in the pattern of alcohol use among different sexes is common in SEAR as mentioned in the World Health Organization's 'Global status report on alcohol and health 2014'.[2] This difference may also be a cause of the underreporting or decreased use of the health services by the females of this region due to socio-cultural issues. ${ }^{[4]}$ Around $16 \%$ of the sample population was under 30 years of age with alcohol dependence among one-third of this population. This finding corroborates the findings of Hingson et al., [5] which showed that early age of initiation of substance abuse leads to increased lifetime risk of alcohol dependence. The alcohol use in the SEAR countries is mainly the unrecorded alcohol, 'homemade liquor'.[2] In our study, 151 patients belonged to various tribes of Northeast India. As the winemaking culture is common among the north-eastern communities, [6] it is probably the cause of early age of alcohol use among the younger generation in this region. Programmes should be initiated which will help the ethnic people to understand the harmful effects of alcohol use on health and to prevent early use of alcohol. Strict follow-up should be maintained among patients with alcohol dependence after initiation of treatment as they are at high risk of relapse. GI comorbidities, neuropathy, as well as superadded infections presenting as fever and respiratory infection noted in our study are a proven effect of alcohol abuse on the health. ${ }^{[2]}$

\section{Strength}

Reporting from a secondary healthcare setup as in our study is very rare in this part of the region but such data provides the actual picture of the existing pattern of health-related event in a particular region.

\section{Limitations}

Retrospective chart review process and missing data were the limitations.

\section{Implications}

This study showed that alcohol is the most common substance abused and streamlining programmes to create awareness relating to the health effects of alcohol and preventing its early use is expected.

\section{Future Directions}

Proper training for data collection focusing on the type and number of substance use, the age of onset of use, volume or quantity of use will help to get a more detailed picture of substance use in this region.

\section{CONCLUSION}

This study showed that substance use is equally common in both tribal and nontribal population, and alcohol is the most common substance abused. Although the most common group with alcohol use is the middle-aged population, onefifth of the patients were younger than 30 years. This finding may be associated with the cultural traditions of winemaking among the tribal population which might have led to early age of initiation of alcohol in this region. Proper steps should be taken to make the local population aware of the health effects due to alcohol use and proper follow-up should be done of the patients treated for substance dependence as they have high chances of relapse. Females should be encouraged to seek help for the issues relating to substance use and the associated stigma should also be addressed.

\section{ACKNOWLEDGEMENTS}

Dr. Linda Cottler and the FOGARTY team, INDO-US program in chronic non-communicable diseases (CNCDs) \#D43TW009120 (M Hazarika, Fellow)

\section{REFERENCES}

[1] Medhi GK, Hazarika NC, Mahanta J. Tobacco and alcohol use among the youth of the agricultural tea industry in Assam, India. Southeast Asian J Trop Med Public Health 2006;37(3):581-6.

[2] World Health Organization. Global status report on alcohol and health 2014. Geneva: World Health Organization: 2014 [cited 2016 Dec 20]. http://apps.who.int/iris/bitstream/10665/112736/1 /9789240692763_eng.pdf

[3] World Health Organization. The ICD-10 classification of mental and behavioural disorders: clinical descriptions and diagnostic guidelines. 10th rev. Geneva: World Health Organization: 1992.

[4] Buragohain S, Dey R. How big is 'alcohol dependence in women' a problem in North East India: the hidden iceberg? In: Dey R, Das S, Talukdar S, et al. eds. Women \& mental health: scientific update for the 26th Annual Conference of the Assam State Branch of the Indian Psychiatric Society. Guwahati: Academy Publisher 2016: p. 114-6. 


\section{Jemds.com}

[5] Hingson RW, Heeren T, Winter MR. Age at drinking onset and alcohol dependence: age at onset, duration, and severity. Arch Pediatr Adolesc Med 2006;160(7):739-46.
Original Research Article

[6] Tanti B, Gurung L, Sarma HK, et al. Ethnobotany of starter cultures used in alcohol fermentation by a few ethnic tribes of Northeast India. Indian Journal of Traditional Knowledge 2010;9(3):463-6. 